\title{
A Afro-Latino América em perspectiva comparada
}

Caroline Santos Guedes ${ }^{1}$

SECRETO, María Verónica e GOMES, Flávio dos Santos. (ORGS.) Territórios ao Sul: escravidão, escritas e fronteiras coloniais e pós-coloniais na América. - $1^{\mathrm{a}} \mathrm{ed}$. - Rio de Janeiro: 7 letras, 2017.

\section{Resenha recebida em: 14/05/2019 \\ Resenha aprovada em: .18/10/2019}

O livro Territórios ao Sul organizado por Verónica Secreto e Flávio Gomes foi criado com o propósito de conectar histórias e historiografias de africanos e afrodescendentes no Atlântico sul diante da falta de diálogo sobre a influência mútua entre os processos históricos afro-latinos americanos. Os autores discorrem acerca dos silêncios comuns sobre América negra e o quanto são necessárias colaborações intelectuais para romper com os afastamentos entre os processos históricos negros nas Américas. Além do já consagrado Gilberto Freyre que desde a década de 1930 marcou o campo de estudos com seus esforços na tentativa de comparar histórias, também podemos incluir os organizadores dessa obra enquanto autores que se dedicam a relacionar os territórios negros na América Latina.

Desde 1998 Verónica Secreto vêm pensando no mundo rural brasileiro e argentino, sob a perspectiva comparada, o que deu origem ao livro Fronteiras em movimento: História comparada - Argentina e Brasil no século XIX (SECRETO, 2012), em sua obra a autora não deixa de incluir a população negra que é abordada em um capítulo denominado "Páginas de miséria e suor" sobre a mão-de-obra usada nos campos do Oeste Paulista e de Buenos Aires. Já Flávio Gomes, em trajetória enquanto intelectual negro é um estudioso de diversas faces da história dos africanos e afrodescendentes, seja sobre mentalidades ou as diversas formas de lutas políticas e sociais para a resistência ao sistema escravista e a obtenção de igualdade e cidadania. As histórias comparadas e conectadas se incluíram nas metodologias adotadas pelo autor em suas pesquisas desde o

${ }^{1}$ Doutoranda em História contemporânea I na Universidade Federal Fluminense. Email:Caroline.santosguedes@hotmail.com

\section{CANPHLAC}


ano de 2003, se dedicando principalmente a afro-latino-América. Dentre suas diversas publicações, gostaria de destacar seu artigo sobre a formação de mocambos como uma forma de resistência escrava no Brasil e na Guiana Francesa (GOMES, 2003).

Globalmente, muito se têm produzido sobre a história atlântica negra em uma perspectiva ampla, seja ela transnacional, comparada ou conectada, que opta por privilegiar fluxos e redes, relacionando os fatos históricos, ao invés de isolá-los. Vale destacar a obra de Herbert Klein e Ben Vinson III sobre a escravidão na América Latina e no Caribe e seus desdobramentos (formas de trabalho, comunidades escravas, resistência e mecanismos para a obtenção da liberdade) (KLEIN, VINSON III, 2008). Dale Tomich, trouxe o conceito de Segunda escravidão para explicar a coexistência da escravidão e da industrialização e como ambos os fenômenos apesar de parecerem contrários se complementam na lógica capitalista, mantendo conexões entre as metrópoles industriais e as colônias fornecedoras de matéria-prima através da mão-deobra escrava (TOMICH, 2011).

Nesse contexto de histórias atreladas, entrelaçadas e relacionadas se encaixa a coletânea organizada por Verónica Secreto e Flávio Gomes, a mesma se inicia com dois artigos situados no espaço bonaerense colonial. O primeiro artigo "Afro-porteños propietarios de inmuebles a fines del siglo XVII - princípios del siglo XVIII” de Miguel Rosál se baseia em fontes inéditas que são as chamadas escribanías antiguas de 1584 até 1756 (documentos de posse de propriedades, compra e venda de escravos e terras censos, recibos de dotes, doações e testamentos) que permitiram ao autor traçar um perfil do contingente negro da cidade, os locais onde esses costumavam morar, suas profissões e configuração familiar. Rosál conclui que muitos negros e mulatos construíram famílias, foram proprietários de imóveis e construíram suas próprias casas, mesmo que em áreas mais marginais pois o valor era mais acessível.

O segundo artigo é de autoria de María Verónica Secreto "Espaços plebeus na cidade colonial: a população negra e mulata de Buenos Aires" e a autora propõe uma análise dos locais ocupados pelos africanos e afrodescendentes que estavam chegando cada vez em maior número em Buenos Aires por meio do tráfico de escravos em meio a um projeto de civilização e modernização da cidade no qual os negros não estavam incluídos. Através dos censos de 1744 e 1778, Secreto conclui que muitas mulheres eram chefes de seus domicílios, havia negros inquilinos de quartos e outros proprietários de

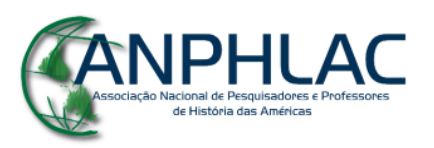


imóveis nas áreas menos nobres, conforme já fora afirmado por Rosál. A autora destaca que muitas vezes as moradias negras localizavam-se nas bordas das valas, região altamente poluída, por isso a mesma usa o conceito de racismo ambiental, pois a população negra é marginalizada até nos locais de moradia. A inovação dessa pesquisa se baseia na sua interdisciplinaridade através da utilização de conceitos de sociologia ambiental e ecologia política.

Em "La población afrodescendente en la conformación agraria del Paraguay hasta la guerra contra la triple alianza", Ignacio Telesca começa destacando o álbum fotográfico em comemoração ao centenário da guerra em 1811 editado por Héctor Decoud no qual os afro americanos não estão englobados, o que pôde ser percebido foi um discurso de homogeneidade étnica no qual o negro não predominou. Diante disso, Telesca busca compreender como se deu essa homogeneidade étnica no campo paraguaio por meio dos registros de venda de escravos e os censos demográficos dos séculos XVII, XVIII e XIX que confirmam a existência da população africana e afrodescendente no meio rural paraguaio como arrendatários ou ocupando comunidades indígenas, o que propiciou a mestiçagem biológica e a integração social dos povos paraguaios.

O quarto capítulo "Afrodescendientes en las comunidades de la frontera uruguayo-brasileña tras la abolición de la esclavitud, el caso de la família Pírez de la Villa de Rocha" de Carla Chagas e Natalia Stalla resgata a vida de uma família afro americana por meio de fontes judiciais sob o olhar da micro-história. As autoras ressaltam que o trabalho com tais fontes possibilita a percepção do escravo ativo, que constrói família, redes de solidariedade, cultura e formas de resistência. Além disso, considero que as autoras conseguiram recuperar costumes da sociedade em que vivia a família Pírez.

No quinto capítulo "Escribir yo: mimesis y autobiografia em Jacinto Ventura de Molina" Alejandro Gortázar se dedicou a recuperar textos que foram escritos por um afrodescendente no Rio da Prata na primeira metade do século XIX - Jacinto Ventura, e que são considerados autobiográficos já que a trajetória de Ventura atravessa seus textos, fazendo com que ele adquira consciência de si e de seu entorno. Jacinto Ventura teve uma trajetória marcada pela cultura espanhola e de gratidão a seu amo que lhe ensinou a escrever, em oposição surge a figura de Juan Francisco Manzano que viveu em Cuba como escravo e aprendeu a escrever burlando seu amo, como uma forma de resistência. Diante das duas figuras que reagiram de forma antagônica à subordinação, Alejandro

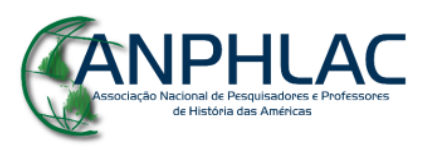


Gortázar pontua o quanto é fundamental estar atento aos processos de aculturação, deculturação e hibridismo cultural nas biografias produzidas por sujeitos subalternos no mundo colonial.

O capítulo de Paola Orías intitulado de "“"Manuel de la Cruz disse ser casi negro y no índio" Estratégias de negociación indentitária de la población afrodescendente ante la justicia charqueña (siglos XVII - XVIII)" se dedica a pensar nas hierarquias sociais de Charcas, na Bolívia, essa é uma sociedade composta por castas, porém segundo Orías esses estamentos são móveis e permeáveis, o que permitia que pessoas com vantagens ascendessem na hierarquia mesmo que sua condição não as favorecessem. As identidades assumidas pelos sujeitos para ressignificar a realidade foram fundamentais, inclusive na busca da liberdade por meio de processos judiciais.

Ainda no território boliviano, Newman Caldeira em seu capítulo "Cativos asilados: direito de propriedade, liberdade e condição legal nas relações diplomáticas do Império do Brasil com a República da Bolívia, 1829-1867” se atém à problemática da posse de escravos entre o Brasil e a Bolívia durante quase quatro décadas, já que muitos escravos pertencentes aos senhores brasileiros cruzavam a fronteira boliviana em busca da liberdade. A Bolívia por sua vez aceitava o asilo dos cativos e não os devolvia ao solo brasileiro.

O capítulo "A mão-de-obra escravizada e os espaços das manufaturas das carnes no Rio Grande do Sul” de Ester Gutierrez trata da publicação de Antônio J. Gonçalves "Memórias ecônomo-políticas sobre a administração pública no Brasil" de 1822, onde o autor se posiciona contra o regime escravista que dizia ser incompatível com a economia moderna, considerando-a uma economia do desperdício, já que há investimento na compra do escravo e na sua manutenção. Em contrapartida as fábricas de Gonçalves e seus filhos contavam com mão-de-obra escrava, inclusive depois da emancipação dos escravos em Pelotas, 1884. É uma real contradição entre o discurso e a prática.

María Eugenia Chaves em "libertad y esclavitud en el contexto de la independência: El caso del Ecuador" demonstra que muitos escravos trabalhavam nas plantations comandadas pelos jesuítas até 1767 quando estes foram expulsos da Espanha e seus domínios, logo as fazendas passaram a ser administradas pelas elites que exploraram os escravos de maneira mais sistemática, por isso muitos protestavam em prol de uma ideia de liberdade. Liberdade essa entendida por eles como a escravidão que eles

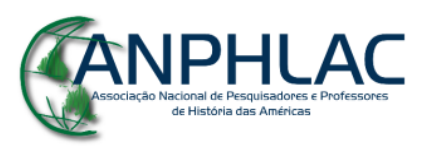


eram submetidos durante a gestão jesuítica que respeitava a divisão e tempo do trabalho, ou seja, essa pode ser entendida como uma liberdade consuetudinária, que foi constituída através das práticas dos jesuítas que difere de liberdade legal, direta e efetiva.

$\mathrm{O}$ artigo de Ezequiel Adamovsky “A cor da nação argentina: conflitos e negociações na definição de um ethnos social. Da crise de 2001 ao Bicentenário da Independência" é acima de tudo útil e atual para entendimento da sociedade bonarense que ainda hoje ainda é questionada sobre a presença dos negros. Adamovsky explica a imagem construída em fins do século XIX de extinção dos ameríndios e africanos diante da imigração europeia e da política de branqueamento para apagar qualquer ameaça a cultura branca que estava sendo construída. Mas ainda na década de 1970, pós-ditadura militar houve uma série de crises trabalhistas e de pertencimento que colocam em xeque a noção de argentinidade, logo emergiram movimentos buscando a afirmação cultural dos povos originários, sua presença, uma reetnização que pôde ser observada por meio da música e da religião. Porém o que o autor ressalta é que a identidade negra em Buenos Aires se refere a uma identidade de classe, não étnica, essa é uma identidade assumida pelos pobres.

O último artigo é de Flávio Gomes e Mariana Rincón chamado "Escravização e emancipação no Brasil e Venezuela: perspectivas comparadas” e reflete a ideia de nação, Estado nacional e pensamento colonial através da perspectivas de fluxos. Os autores percorrem as historiografias da escravidão, processos emancipacionistas e cidadanias de ambas as regiões que propuseram abordar.

Entendo que tal obra foi publicada na perspectiva de permitir maior conexão entre as histórias negras latino-americanas durante o período escravista e pós-emancipação, por isso devemos destacar sua colaboração na promoção de promissores diálogos entre historiadores que pesquisam populações negras e seus modos de vida, identidades, posses, redes de solidariedade, formas de resistir e se organizar. É preciso atentar para o fato que tal coletânea deu voz aos povos africanos que foram submetidos ao processo de diáspora e seus descendentes, mesmo que muitas vezes só houvesse a disponibilidade de documentação oficial. À título de conclusão, atento aos organizadores a pensarem em publicações futuras de outros volumes da coletânea dividindo o livro em temáticas comuns, mantendo a permanência de artigos de pesquisadores de diferentes regiões do Atlântico sul.

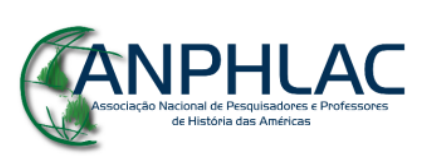




\section{Referências Bibliográficas}

KLEIN, Hebert; VINSON III, Ben. La esclavitud Africana en América Latina y el Caribe. Lima: IEP, 2008.

SECRETO, María Verónica. Fronteiras em movimento: História comparada - Argentina e Brasil no século XIX. $1^{\mathrm{a}}$ ed. Niterói: EdUFF, 2012.

TOMICH, Dale. Pelo prisma da escravidão: trabalho, capital e economia mundial. São Paulo: EdUSP, 2011.

GOMES, Flávio. Other black atlantic border: Escape routes, mocambos and fears of sedition in Brazil and French Guiana (Eighteenth to nineteenth centuries). New West Indian Guide, Caribe, V. 77, Nº:34, pp 253-287, 2003.

\section{GANPHLAC}

